\title{
LAS GALERÍAS, CONSTRUCCIONES PARA ALUMBRAR AGUA DE FREÁTICOS PRÓXIMOS EN EL NE DE LA REGIÓN DE MURCIA: MINADOS CON ESPEJUELOS EN JUMILLA
}

\author{
J. Ma . Gómez Espín, E. Gil Meseguer, I. Aliaga Sola, J. A. López Fernández y \\ R. Martínez Medina' \\ Departamento de Geografía \\ Universidad de Murcia
}

RESUMEN

En el Sureste de la Península Ibérica, existen áreas que no cuentan con recursos de aguas en superficie, por lo que para el abastecimiento de la población y ganado, así como para el riego, tradicionalmente se ha recurrido al aprovechamiento de freáticos mediante sistemas de galerías filtrantes «qanat-s»; llamados también galerías con lumbreras y en el NE de la Región de Murcia «minados con espejuelos».

En el término municipal de Jumilla (Murcia) se han localizado varios de estos sistemas: Montesinos, La Pedrera, Las Puntillas, La Alquería, Los Manaores, Fuente del Pino, Los Estanquicos, Los Álamos, Los Inques,... Cada uno de ellos ha constituido un sistema local de recursos propios de agua en un medio árido y semiárido como el Sureste.

Palabras clave: galerías filtrantes, minados con espejuelos, aguas subálveas, NE de la Región de Murcia.

\begin{abstract}
Some areas in the South-East of the Iberian Peninsula lack surface sources of water. As a result of this, aquifers near the surface have been exploited by means of percolating galleries ('quanat-s»), also called 'galleries with embrasures' and 'galleries with skylights' in the North-East of the Region of Murcia. These have fulfilled the needs of agriculture, stockbreeding and the population in the area.

Several galleries have been found in the municipality of Jumilla (Murcia): Montesinos, La Pedrera, Las Puntillas, La Alquería, Los Manaores, Fuente del Pino, Los Estanquicos, Los Álamos, Los Inques... All of them are local systems that exploit their own water resources in an arid and semi-arid environment.
\end{abstract}

Key words: draining galleries, qanat-s, water from aquifens near the suface, NE Region of Murcia.

- Esta investigación forma parte del Proyecto 9223 «Sostenibilidad de aprovechamientos de aguas subálveas en la Región de Murcia». Convenio entre la Universidad de Murcia y la Consejería de Industria y Medio Ambiente de la C.A.R.M. 


\section{Introducción}

En el NE de la Región de Murcia (Altiplano Jumilla-Yecla), junto a la escasez de precipitaciones y elevada evapotranspiración, hay que unir un roquedo calizo que favorece la infiltración. Estos factores dan como resultado que los cursos superficiales apenas lleven agua unas horas, unos días tras precipitaciones abundantes y de elevada intensidad horaria. En estos casos las aguas pluviales, a través de algunas ramblas como las de El Judío y la Raja-El Moro, llegan al alejado río Segura.

La carencia de cursos de agua permanente ha hecho que la población, desde tiempo inmemorial, haya recurrido a los manantiales y a los sistemas de captación de corrientes subsuperficiales para poder disponer de unos recursos hídricos básicos.

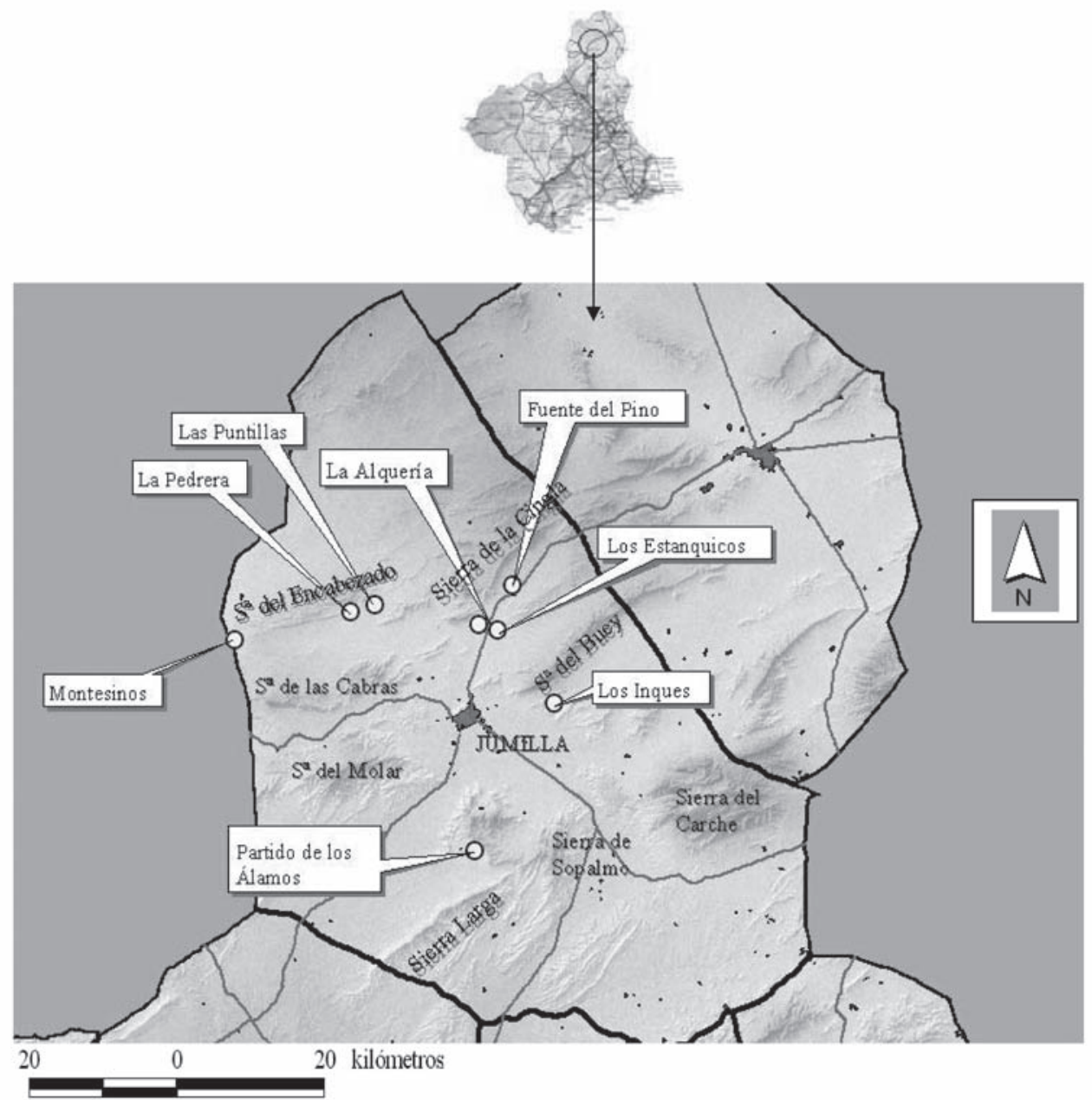

FigURA $\mathrm{N}^{0}$ 1. Localización de galerías o «minados con espejuelos» en Jumilla 
Los anticlinales, pertenecientes al Prebético autóctono con dirección predominante NESW, delimitados y fracturados por fallas, originan unos relieves que oscilan entre los 800 y 1.400 metros de altitud, desde donde amplios glacis descienden hasta el nivel rellenado por materiales neógeno-cuaternario. Los puntos más deprimidos son ocupados por cauces temporales, siendo los más importantes las ramblas de la Raja y el Judío. Entre estos relieves se encuentran corredores naturales donde se inserta la red caminera tradicional y actual, utilizada en tiempos pasados por la actividad ganadera con sus cañadas, cordeles y veredas. El Altiplano es en cierta forma un lugar de transición entre las tierras castellanas de la Meseta, el litoral del Sureste, así como el corredor de Levante que uniría los reinos de Granada y Aragón.

Es en estas geoformas (glacis y ramblas) donde los antiguos pobladores buscaron su aprovechamiento hídrico.

Se han encontrado construcciones hidráulicas, de distintas épocas, repartidas por todo el territorio municipal. Resaltan, junto a aljibes y otros tipos de almacenamiento, los sistemas de captación y conducción de aguas como las «GALERÍAS CON LUMBRERAS» (conocidas y denominadas por los lugareños como «MINADOS CON ESPEJUELOS»). Estos sistemas han configurado auténticos aprovechamientos que han surtido de agua tanto a la cabecera urbana principal (Jumilla) como a algunos núcleos rurales, caso de La Alquería o La Fuente del Pino.

El objeto de este trabajo es analizar y describir algunos de ellos. (Figura 1).

\section{Sistema de galerías con lumbreras formado por «la Pedrera» $\mathbf{y}$ «las Puntillas»}

Dos de las construcciones más importantes, que han originado un sistema unitario de captación y distribución de aguas, ha sido el formado por las galerías de La Pedrera y de Las Puntillas. Ambas galerías se encuentra en desuso hoy en día, pero no hace muchos años, eran un sistema de aprovisionamiento de aguas de la población y para el riego de tierras en Jumilla.

Se localizan en la carretera que va de Jumilla a Ontur. La primera, denominada de «La Pedrera», desciende de la Sierra de la Pedrera y llega hasta las inmediaciones de la Casa del Cura, y la segunda tiene su nacimiento en el Puntal de la Librería (sector oriental de la Sierra de la Pedrera), llamándose de «Las Puntillas»; desciende, cruzando la carretera anteriormente citada, para desaguar en un balsa circular. Ambos caudales eran conducidos aguas abajo para formar uno y regar más de 60 hectáreas.

La galería de La Pedrera evacua sus aguas en una balsa situada unos 500 metros más abajo de la Casa del Cura. Hoy en día, esta balsa está muy deteriorada y el último tramo de la galería está destruido. Incluso ha sido roturado y cultivado.

Tiene una longitud de 3.460 metros, siendo una de las más largas encontradas en este espacio. Cuenta con 64 lumbreras para poder acondicionar la galería (construcción, limpieza, ventilación,...). La profundidad de esta galería oscila entre algo más de 50 metros de las primeras lumbreras a menos de 2 de las últimas, ya próximas a la antigua bocamina, hoy en día destruida.

La galería de Las Puntillas evacua sus aguas a una balsa también circular dentro de la finca de la Casa de Las Puntillas donde además hay una balsa cuadrada de construcción más reciente. Desde la alberca circular hay un canal a cielo abierto que trascurre por la orilla de la actual carretera de Jumilla a Ontur. Antes de unirse con el canal de las aguas de La Pedrera, las aguas de «Las Puntillas» descansan en la «Balsa de las Puntillas», situada a unos 500 metros de distancia de la primera balsa, totalmente destruida y casi borrada por el tiempo (construcción antigua hecha en mampostería). 
Esta galería tiene una longitud de 1.300 metros y 29 lumbreras. Las dimensiones son algo menores que la anterior, pero la situación de la galería y la alineación de las lumbreras (descendiendo del piedemonte del Puntal de la Librería y cruzando por debajo de la carretera) hace que sea una de las más vistosas de este territorio.

La localización de estos sistemas coincide, además, con corredores naturales utilizados desde época antigua por los viajeros y pastores trashumantes para llevar sus productos y ganados de un lugar a otro, dependiendo de la estación del año. Esta es una de las características de este espacio, ya que la mayoría de los puntos de aprovechamiento de aguas se localizan cercanos a antiguas veredas y/o cañadas reales.

La documentación encontrada en la Comisaría de Aguas no ofrece información sobre la galería de las Puntillas. Sin embargo, la galería de La Pedrera, según estos documentos, tenía un caudal de 4 litros por segundo y servía para regar una superficie de más de 60 hectáreas. Las galerías se asientan sobre el acuífero «Escamas y Diapiros Alcazar-Ontur», y pertenecía a la Comunidad de Aguas «Pozo Artesiano de la Pedrera», cuyo reglamento fue concertado el 5 de junio de 1.951. Los datos registrados sobre las dimensiones de la galería, en cuanto a su longitud, no coinciden con la real del sistema, ya que se contabilizan 1.400 metros, frente a los 3.460 metros medidos en superficie actualmente. Hoy en día, las aguas ya no corren por estos sistemas, y presentan un lamentable estado de deterioro, incluso como ocurre con el tramo final de La Pedrera, ha sido destruido y suplantado por unas parcelas de cultivo.

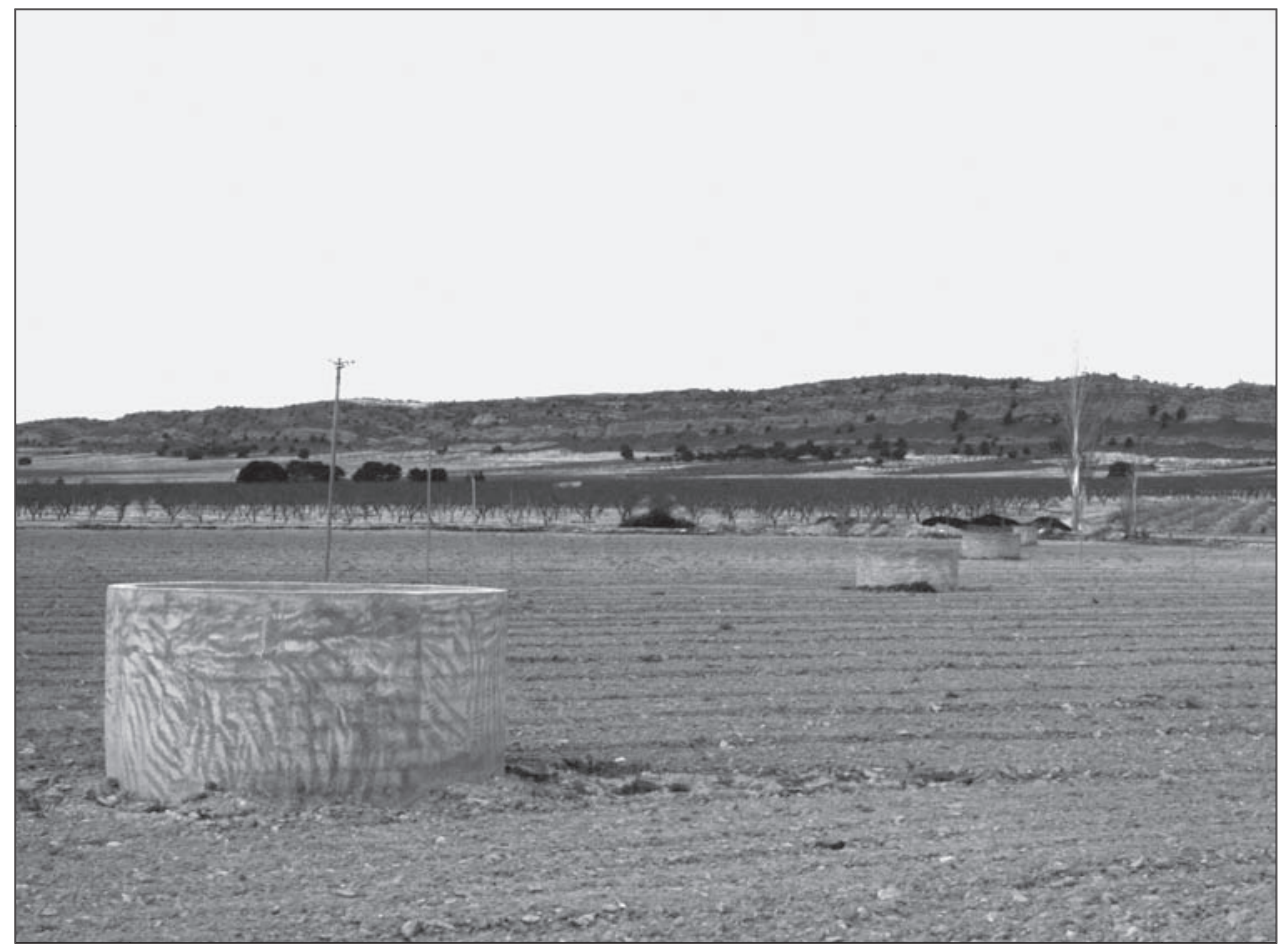

Ғото $\mathrm{N}^{\mathrm{o}}$ 1. Últimas lumbreras de la galería de la Pedrera, reforzadas en superficie. 
Sin embargo, no hace muchos años las aguas brotaban por estos minados y daban lugar a tandas de riegos que constaban de catorce días cada una; de un día cada cinco acciones siendo el total de que consta la mancomunidad setenta acciones. Además de dar riego a 60 hectáreas, servía para el riego de socorro de más de 514 hectáreas de la zona, regando tierras blancas y viñedo, con un volumen máximo anual de $5.000 \mathrm{~m}^{3} / \mathrm{Ha}$.

En la actualidad, las escasas aguas que se capturan con estos sistemas se aprovechan mediante conducciones con tuberías u otros métodos. Sin embargo, estos minados han sido sustituidos por grandes sondeos que han hecho descender el nivel piezométrico.

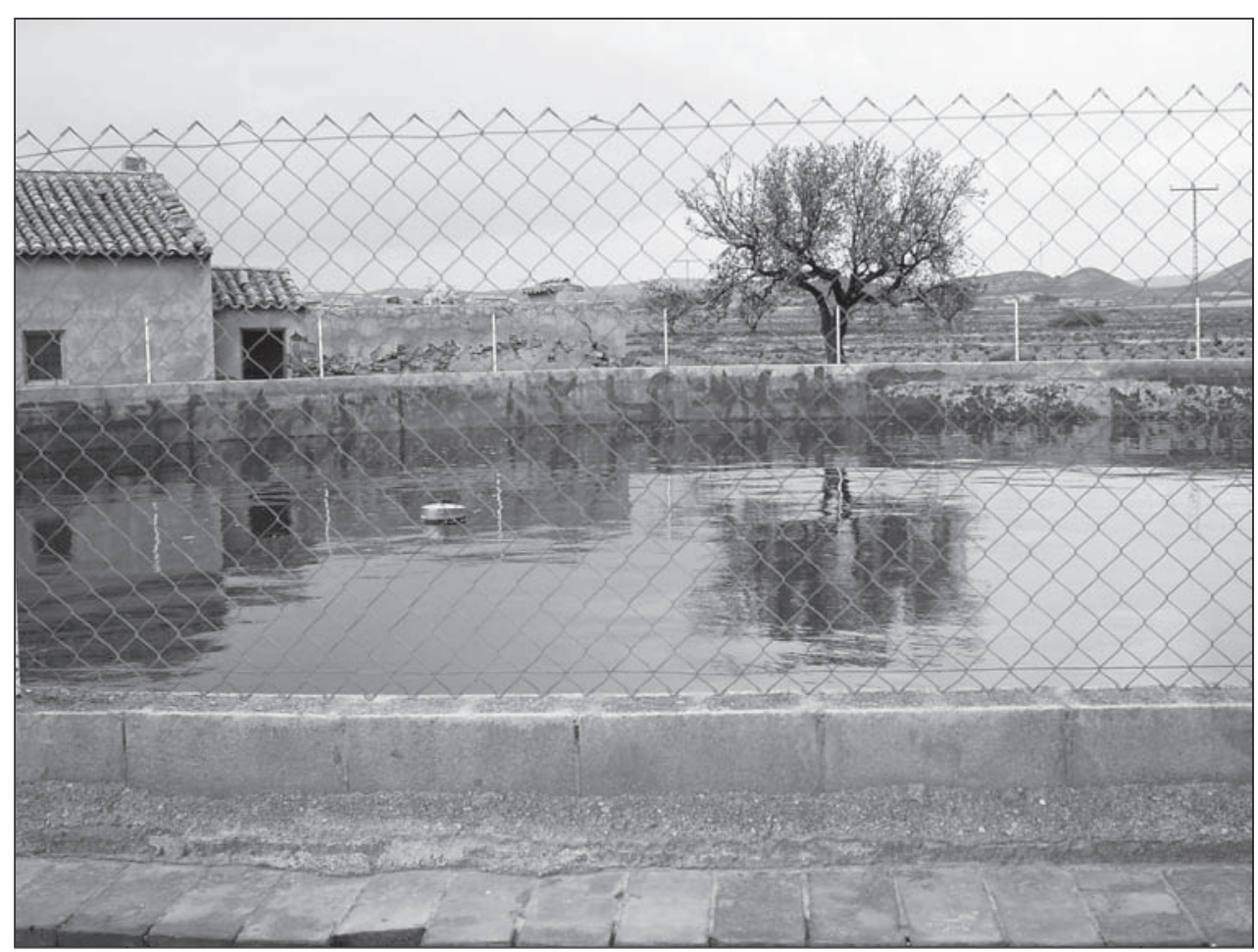

Fото $\mathrm{N}^{0}$ 2. Balsa que recibe las aguas captadas por la galería de Las Puntillas.

\section{Galería de los Pinos en Montesinos, Jumilla}

\subsection{Localización y breve descripción}

Esta galería se encuentra en la aldea de Montesinos, término municipal de Jumilla. Se accede a ella por la carretera que va de Jumilla a Ontur por un desvío a unos 5 kilómetros de Jumilla a la izquierda, a unos 11 kilómetros, en otro cruce de carreteras, nos encontramos el aprovechamiento.

Actualmente está en desuso para el riego, pero sirve para el abastecimiento de ganados que transitan por estos parajes, ya que el agua cae a un abrevadero que hay tras la bocana de la galería, y de este a una balsa. 
La galería, con orientación Sur / Norte ocupa el piedemonte del relieve denominado «Las Hermanas», de 1.000 metros de altitud.

Las coordenadas geográficas y UTM de la localización de la balsa son las siguientes:

\begin{tabular}{|c|c|c|c|c|}
\hline Coord. & \multicolumn{2}{|l|}{ UTM } & \multicolumn{2}{|l|}{ Geográficas } \\
\hline Balsa & $X: 632146.25$ & Y: 4264318.36 & Lat: $38^{\circ} 31^{\prime} 0,33^{\prime \prime} \mathrm{N}$ & Long: $1^{\circ} 29^{\prime} 9,4^{\prime \prime} \mathrm{W}$ \\
\hline
\end{tabular}

\subsection{Condiciones ambientales del entorno geográfico}

La galería se encuentra en los dominios del Prebélico externo, en el acuífero «CinglaCuchillo», al suroeste de un anticlinal que discurre de Este a Oeste.

Estos relieves están formados por materiales calizo-dolomíticos, en contraste con el cuaternario detrítico de los piedemontes.

Las precipitaciones en el territorio oscilan entre los 300 y $400 \mathrm{~mm}$ anuales, repartidas irregularmente en el año. La vegetación natural que aparece fuera y en los bordes de las tierras de cultivo, es de matorral mediterráneo, coscojas, romeros,... y pinos en algunos enclaves.

Es el dominio del secano, con la vid como principal cultivo. La existencia de algunas parcelas de huerta, se debió al aprovechamiento de este sistema de galería y, posteriormente se ampliaron las parcelas con la extracción de aguas subterráneas profundas, a partir de pozos verticales.

El área es un camino natural entre Albacete y Murcia, que discurre entre las sierras del Encabezado y la Pedrera al norte y, la de las Cabras al sur; y fue utilizado por los pastores trashumantes, como lo harían de las aguas que proporcionaban los sistemas localizados aquí en Montesinos, La Pedrera, Las Puntillas y El Cerco.

\subsection{Rasgos del sistema: captación, circulación y distribución}

La galería cuenta con un total de doce lumbreras, que le dan ventilación durante sus casi 400 metros de longitud. (350 según los datos de la inscripción realizada en la Comisaría de Aguas). La galería se encuentra en desuso hoy en día, pero no hace muchos años se construyeron nuevas lumbreras para sustituir las antiguas, derruidas y en mal estado. Se ven así dos tipos de lumbreras; unas más antiguas de diámetro inferior a un metro, con una protección superficial que no sobrepasa los 20 centímetros sobre el nivel del suelo y realizadas con argamasa y ladrillos. Las rehabilitadas tienen un diámetro de 2 metros, construidas con bloques y bovedillas unidas con mortero, y presentan abundantes restos de materiales extraídos en el momento de su construcción.

En cuanto a la distancia entre ellas, es irregular. La primera o pozo madre se encuentra a 57 metros de distancia de la segunda. Esta lumbrera, y las dos siguientes, están en desuso y han sido sustituidas por otras construidas en un punto cercano a ellas con separación de 30 metros, y a 23 metros entre ellas. La quinta lumbrera aparece a 15 metros y presenta gran cantidad de materiales a su alrededor.

La siguiente lumbrera se sitúa a 17 metros y 23 metros después hay una lumbrera en el arcén de la carretera y tiene la forma de un sifón moderno. Igual que al otro lado de la carretera, a 21 metros. La siguiente lumbrera se localiza a 40 metros; después son 50 metros y a 32 metros la siguiente. Desde esta última lumbrera hasta la balsa hay una distancia de 65 metros, de los cuales los últimos trascurrían por debajo de un pequeño camino de tierra. Antes de llegar las aguas a la balsa, descansan en un pequeño abrevadero utilizado también como lavadero, que perdura hoy en día, y que puede ser utilizado. 


\subsection{Contexto geohistórico del aprovechamiento}

No hay datos referidos al año de construcción de la galería; debió de realizarse por la época que el caserío. Este comprende los ejidos denominados «Montesinos»; «El Cuartel»; «La Venta», y «Los Pinos».

En el registro de la Comisaría de Aguas de 28 de enero de 1988, se describe el aprovechamiento diciendo que el agua discurre por gravedad a través de una galería subterránea de 160 metros hasta un embalse de unos $350 \mathrm{~m}^{3}$ de capacidad. Se apunta un caudal en ese año de 1 litro por segundo. La superficie regable en ese momento (principios de los 90 del siglo XX), rondaba las 5 hectáreas. Sin embargo, recientemente (año 2006), la galería tenía un pequeño hilo de agua saliendo por la bocamina y, sólo algunas lumbreras presentaban agua en su interior que reflejaban la luz como un «espejuelo». En estas condiciones, de las 190 hectáreas de la finca, sólo se puede regar una pequeña huerta. Sobre todo es utilizada para el ganado, que tiene su abastecimiento asegurado por la escasa fluctuación del caudal a lo largo del año. Los titulares de este aprovechamiento eran las señoras $\mathrm{M}^{\mathrm{a}}$ Clara Pérez de los Cobos y Espinosa de los Monteros, María Dolores Espinosa de los Monteros y Gonzáles Conde y María Noguera y Espinosa de los Monteros.

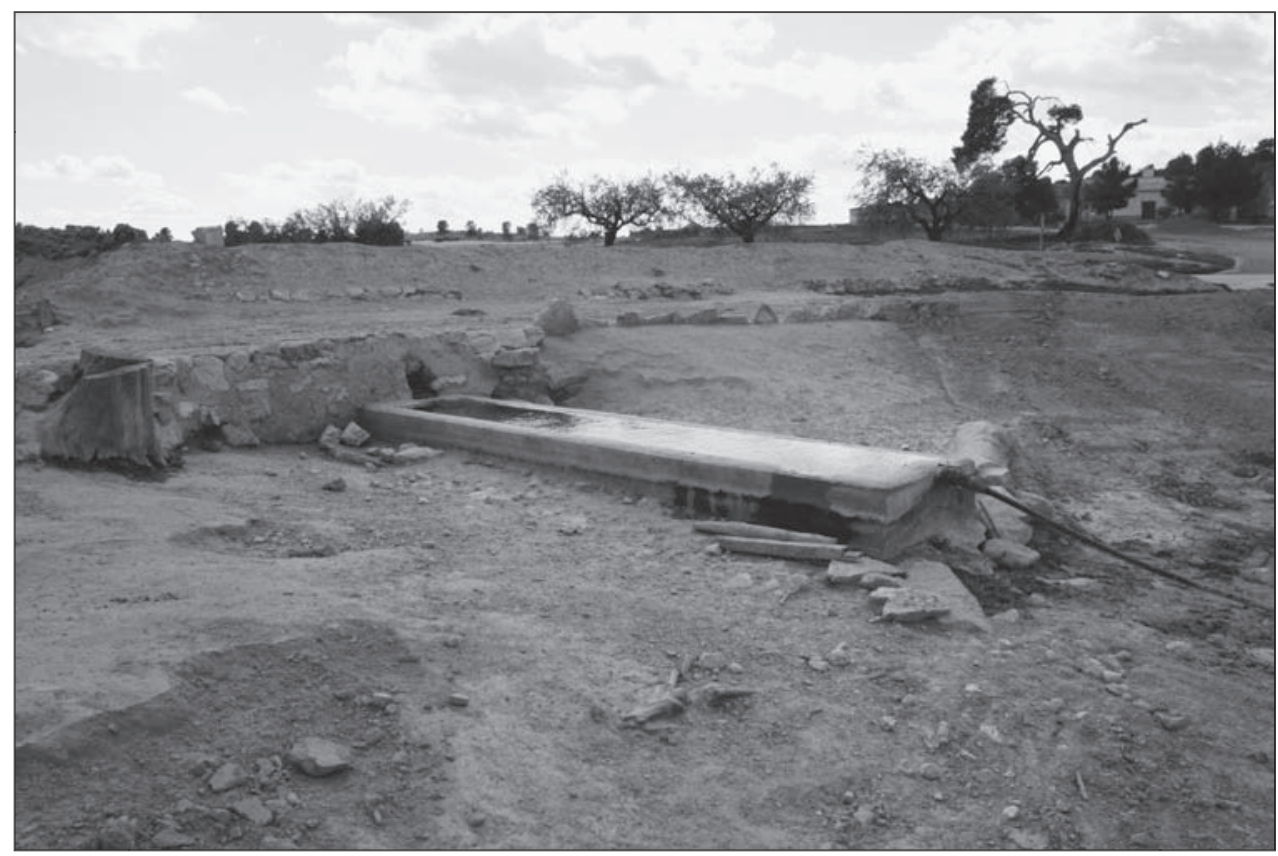

Fото No 3. Estado actual del abrevadero en la galería de los Pinos, en Montesinos.

\subsection{Estado actual y observaciones}

La galería está abandonada en algunos de sus tramos. Incluso se observa que en algún momento se intentó recuperar el sistema construyendo nuevas lumbreras como se aprecia por los materiales más recientes y, realizando nuevas conexiones entre las mismas. Sin 
embargo, los derrumbes y desprendimientos de la galería impide que el caudal captado circule libremente. Las filtraciones posibilitan que un pequeño hilo de agua siga cayendo en el abrevadero situado después de la bocamina. Además, la extracción de aguas profundas en este espacio jumillano ha hecho descender los niveles freáticos, dejando en desuso estos sistemas, salvo cuando se producen intensas precipitaciones, que se filtran en el suelo y son captadas por los minados.

El estado de la balsa es descuidado. Está excavada en el terreno aprovechando la topografía, sin ningún tipo de muro. Hoy en día, apenas puede retener caudal y el agua se capta mediante una manguera desde el abrevadero para conducirlas a tierras más abajo.

Los caseríos cercanos se utilizan para guardar los aperos de labranza y algunas cabezas de ganado, sin la importancia de otros tiempos pasados en los que significaban puntos de agua en el paso de los ganados. Hoy en día, las aguas de este aprovechamiento se destinan al riego de una pequeña huerta (no la tradicional que se encuentra abandonada), para abrevar algunos ganados, así como bebedero de pequeños roedores y otros animales de vuelo y suelo que habitan en el lugar.

\section{Minado con espejuelos del partido de los Álamos}

\subsection{Localización y breve descripción}

Esta galería se localiza en el paraje de los Álamos, en el término municipal de Jumilla, en el piedemonte sur de la Sierra de los Alacranes. Se llega a ella por un camino rural, recientemente asfaltado, que se encuentra a la izquierda en la carretera de Jumilla a la Venta del Olivo. El camino para llegar al piedemonte donde se encuentra el paraje y la galería de los Álamos, cruza la rambla del Judío, cuyo lecho se encuentra aterrazado y cultivado de diversos frutales (perales, melocotoneros, vides,...). Una vez aquí veremos la balsa a la derecha, a continuación, en el margen izquierdo de la carretera se encuentra la bocamina y primeras lumbreras de la galería. La orientación de la galería es de NE a SW; dirección característica de los relieves béticos.

\begin{tabular}{|c|c|c|c|c|}
\hline Coord. & UTM & & Geogr & \\
\hline Balsa & X: 644443.68 & $Y: 4250551.25$ & Lat: $38^{\circ} 23^{\prime} 37,84^{\prime \prime} \mathrm{N}$ & Long: $1^{\circ} 20^{\prime} 44,37^{\prime \prime} \mathrm{W}$ \\
\hline
\end{tabular}

\subsection{Condiciones ambientales del entorno geográfico}

La galería se encuentra excavada en el material detrítico del glacis, que desciende desde la solana del relieve de los Alacranes (extremo suroccidental de la sierra de Santa Ana) con dirección SW-NE.

El espacio pertenece al acuífero del sinclinal de Calasparra y desde antiguo se utilizaron las aguas de un manantial cercano, pues hay una balsa romana, así como un abrevadero para el ganado que aún se conserva.

\subsection{Rasgos del sistema: captación, circulación y distribución del agua}

El aprovechamiento de esta galería ha servido para regar una pequeña parte de las 65 hectáreas de la finca en la que se encuentra, según información del anterior propietario Sr. D. Juan Tomás. 
La obra está fechada el 24 de julio de 1907, aunque hace unos años se reconstruyeron las bocanas de las lumbreras, como también se protegió un hundimiento de la galería, cerca de la bocamina, con un vallado.

La primera lumbrera o pozo madre de este sistema se encuentra en un área de erial, situada entre terrazas de cultivo, ocupada por la vegetación arbustiva autóctona. Es una lumbrera (cubierta de sedimentos) con una profundidad de 2 metros, que según el antiguo propietario de la finca, es una lumbrera a medio construir, con el fin de alargar la galería.

A 20 metros, se encuentra la segunda lumbrera, presentando agua circulante en su interior. Tiene una profundidad de 9,20 metros y un metro de diámetro. A su alrededor se acumulan los materiales extraídos y la protección superior es cuadrada, aunque el pozo es circular. Como ocurre con el resto de las lumbreras, solo la parte superior (de 50 centímetros a un metro) se encuentra realizada de obra; el resto está excavado sin ningún tipo de protección.

La siguiente lumbrera se encuentra a 31 metros de distancia. Tiene una profundidad de 8,70 metros y un metro de diámetro. Al igual que la anterior lumbrera, se observa agua circulante en su interior. A 26 metros se encuentra la número 4 con una profundidad de 7,60 metros y un metro de diámetro.

Tras cruzar un camino rural y a 22 metros, aparece la siguiente, que es utilizada como pozo ya que tiene una pequeña caseta donde se sujeta un travesaño utilizado para amarrar una garrucha y extraer el agua con un cubo, con la cual llenar un pequeño abrevadero de ganado inmediato. Tiene una profundidad de 7,50 metros y 1,20 metros de diámetro.

La sexta lumbrera la encontramos a 40 metros en una parcela cultivada de almendros. Como las anteriores, está protegida con una reja, es de sección cuadrada en superficie y circular hacia el interior, con una profundidad de 6,60 metros y un metro de diámetro.

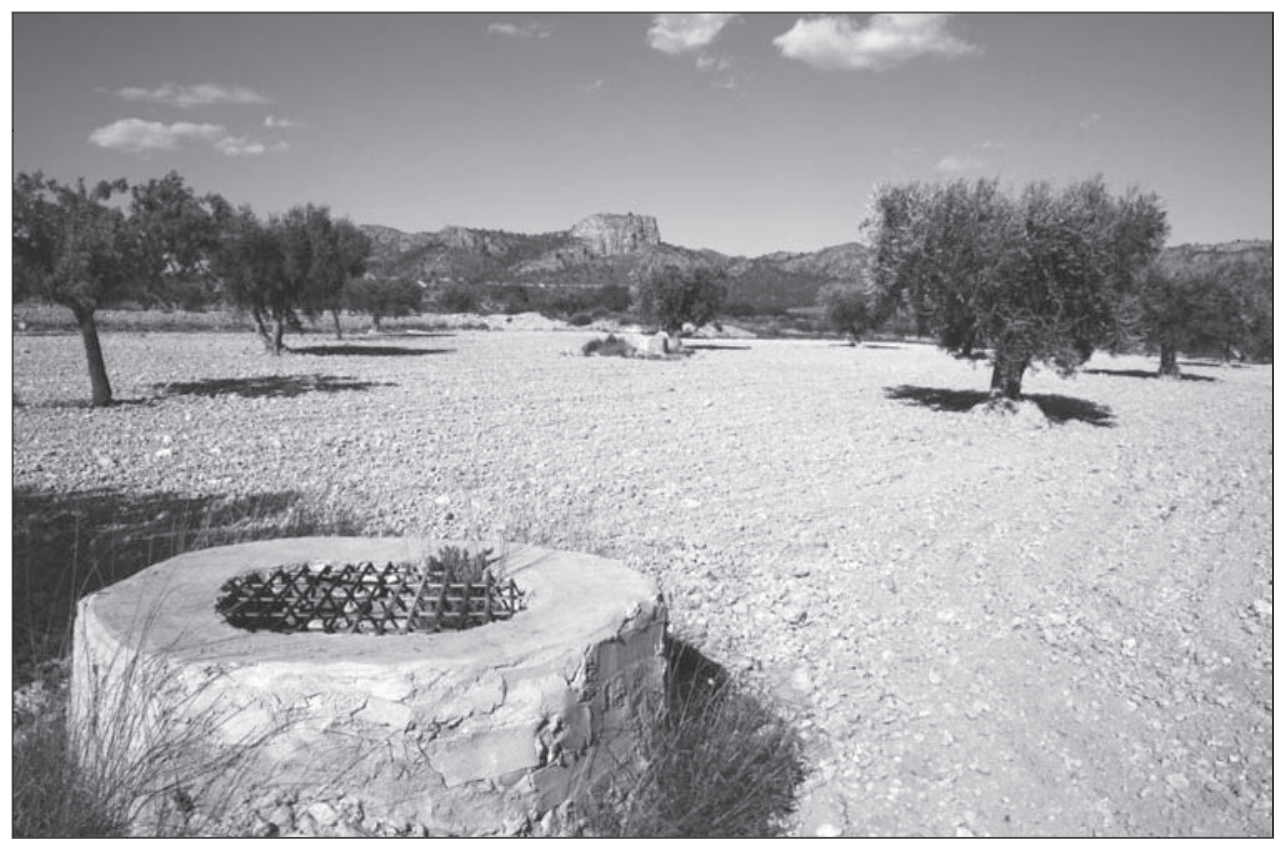

Fото No 4 . Lumbreras alineadas de la galería de los Álamos. Al fondo observamos la cumbre de la Sierra de Santa Ana. 
El séptimo pozo se encuentra a 40 metros, tiene 5,80 metros de profundidad e igualmente un metro de diámetro. A 30 metros está la siguiente con una profundidad de 4,40 metros. A 35 metros se encuentra un tramo de galería hundido que ha sido protegido con una valla para evitar caídas, que se mantienen limpios de sedimentos para permitir el paso del agua.

La salida de la galería se halla a 39 metros y está protegida por una valla que no permite acercase. Tras aflorar la galería, el conducto se entuba para salvar una carretera y volver a la superficie, ya a escasos metros de la balsa que acumula sus caudales. Ésta es de sección rectangular, 20 metros de largo y 12 de ancho y con una profundidad de 1,50 metros (Figura $\mathrm{n}^{\mathrm{O}} 2$ ).

Según Juan Tomas, la balsa tardaba un mes en llenarse, y en verano más. Según los datos de la Confederación Hidrográfica del Segura, el caudal aflorado por el sistema es de $0,5 \mathrm{l} / \mathrm{seg}$. y un caudal medio equivalente de $0,38 \mathrm{l} / \mathrm{seg}$. Estos caudales dan un volumen máximo anual de $12.000 \mathrm{~m}^{3}$, con los que se riegan 5,5 hectáreas de huerta.

\subsection{Contexto geohistórico del aprovechamiento}

Sin duda alguna, los datos y las observaciones que nos realizó el Sr. D. Juan Tomas nos han sido de gran ayuda para conocer y estudiar esta galería con lumbreras. Como ya se ha mencionado, el sistema data del 24 de Julio de 1907, aunque la mayoría de las galerías construidas en estos parajes son anteriores a esta época, incluso hay otros aprovechamientos más antiguos como «El Cerco» alrededor de fines del XVIII, principios del XIX, que suministraba las aguas para la población de Jumilla. En las inmediaciones de la galería de la Umbría de los Álamos, hay restos de construcciones romanas que servían para almacenar y distribuir las aguas de un afloramiento cercano a la galería, que según escritura de 31 de mayo de 1958, se denominaba «Mina de los Olmos».

Según la memoria adjunta por los propietarios, para la inscripción como aprovechamiento de aguas privadas de esta galería, en la Confederación Hidrográfica del Segura el 26 de Diciembre de 1991, en el paraje de los Álamos se encuentran los tres pozos principales productores de las aguas, que son conducidas por una galería hasta una balsa. Se recoge que: «las aguas manan por un propio pozo a través de una galería de 500 metros de longitud y 0,50 metros de anchura, las cuales discurren por las fincas de los propietarios».

\subsection{Estado actual y observaciones}

Se trata hoy en día, de una galería funcional, donde las lumbreras y la galería han sido mantenidas, restauradas y protegidas, además de alargarla con nuevas lumbreras para mejorar el funcionamiento del sistema.

\section{Los sistemas de La Alquería y Fuente del Pino}

Las poblaciones de La Alquería y Fuente del Pino figuran en este estudio como ejemplos de núcleos que con estos sistemas de «minados con espejuelos» se han abastecido tradicionalmente de agua.

Ambas poblaciones se localizan en la carretera N-344 que une Jumilla con Yecla, en el piedemonte orientado hacia el SE de la Sierra de la Cingla, donde aparecen cultivos de vid y almendros, encontrándose aquí las primeras lumbreras de estos sistemas. 


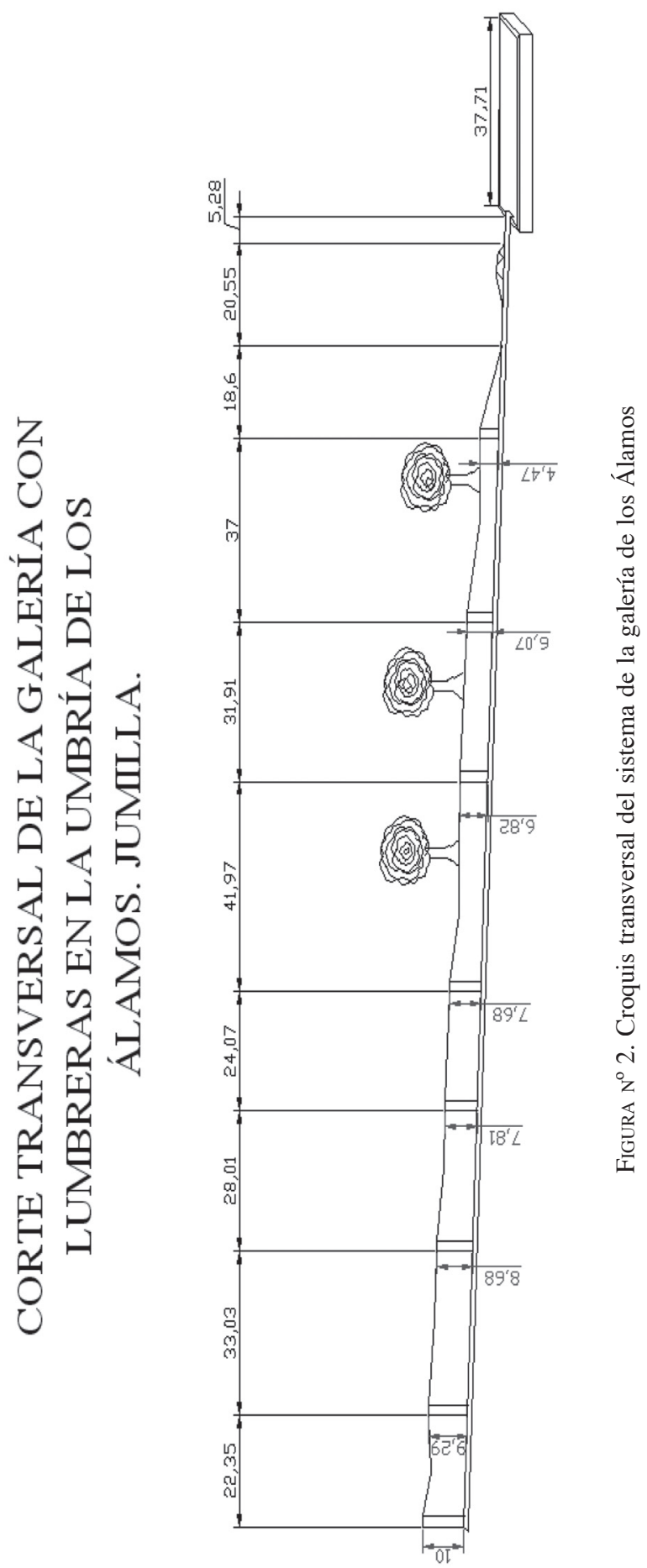




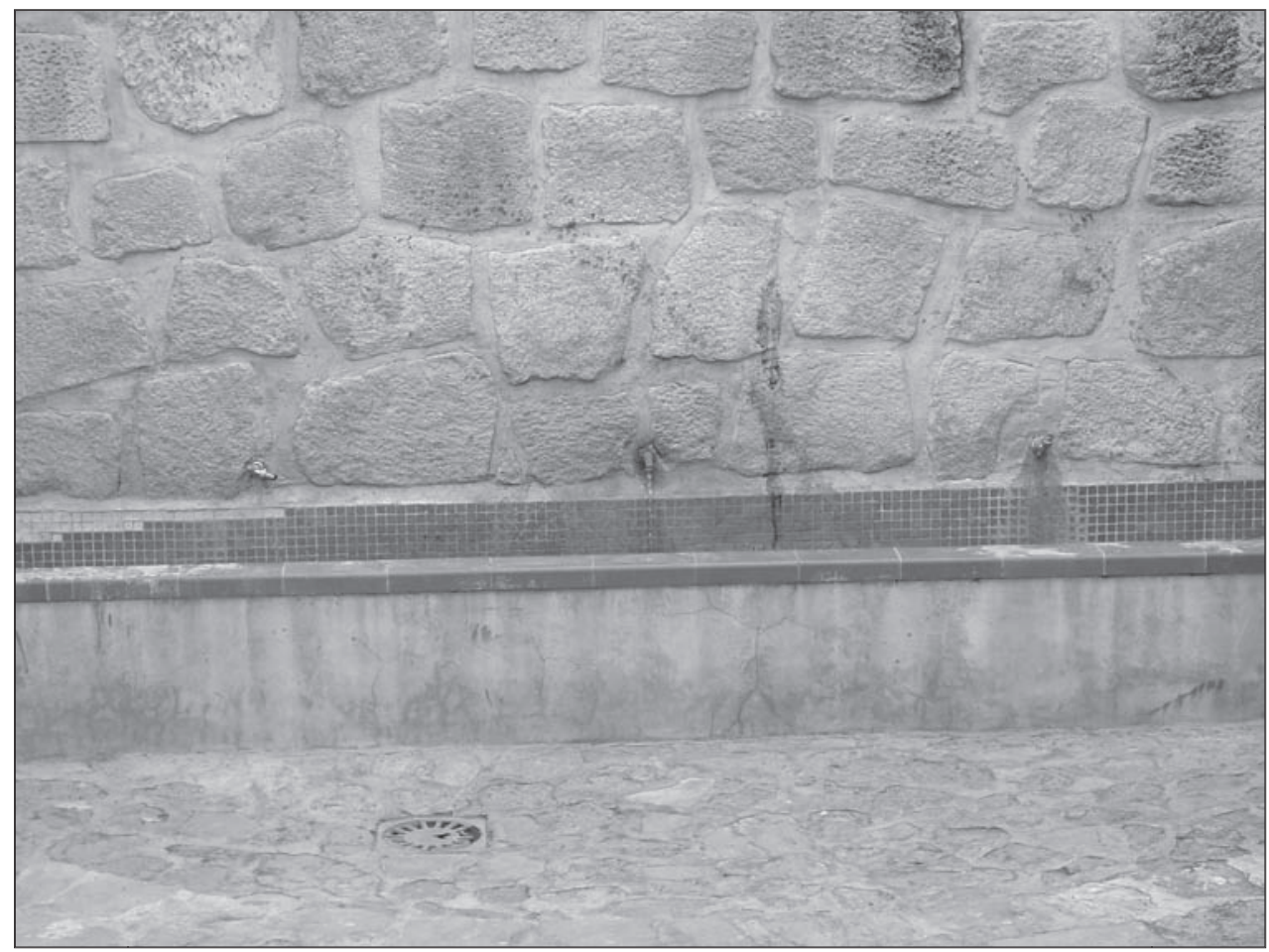

Fото No 5: Caños de la Fuente de La Alquería (Jumilla).

En el caso de La Alquería, la galería consta de 29 lumbreras, todas ellas cegadas por seguridad y protección. Tiene una longitud aproximada de $3 \mathrm{Km}$. y presenta forma de «y griega», con dos ramificaciones. La bocamina coincide hoy con la actual fuente del núcleo, y la balsa de acumulación es utilizada como piscina municipal. Además, siguiendo en línea descendente, hay restos de antiguos molinos que utilizaban la fuerza hidráulica para poner en funcionamiento los aparatos de la molienda.

En el caso de Fuente del Pino, además de la galería que transita subterránea por en medio de la población y que consta de 5 lumbreras, están los restos que componían el sistema de «Los Manaores». De la que se conservan restos de una gran balsa que recogía las aguas de este manantial y unas galerías. También hay un lavadero público. Los «espejuelos» de las galerías de este sistema han desaparecido, pero la existencia de ellos se observa en la fotografía aérea de la zona realizada en el vuelo americano en 1.956, en la que se aprecian 8 lumbreras.

Desde hace unas décadas, estos espacios han sido transformados, sobre todo para acondicionar los nuevos cultivos. Además, con la implantación de nuevos sistemas de distribución junto con la bajada de los freáticos próximos, estos aprovechamientos están siendo olvidados y destruidos. Sin embargo, la conservación de estos sistemas en núcleos rurales como La Alquería y Fuente del Pino puede favorecer el desarrollo sostenible de un recurso tan escaso y necesario, además de mantener unas construcciones que forman parte de un rico patrimonio cultural en el uso del agua repartidas por esta comarca. 


\section{Sistema de la galería con lumbreras de Los Estanquicos}

\subsection{Localización y breve descripción}

Galería o minado con longitud planimétrica aproximada de 400 metros desde cabecera hasta bocamina. Contabiliza un total de 8 lumbreras o espejuelos y una balsa receptora del subálveo alumbrado al final de su recorrido. Este sistema drenante, localizado en pleno paraje de «Los Estanquicos» dentro del término municipal de Jumilla, sitúa su cabecera a unos 593 metros de altitud y su bocamina a algo menos de $584^{1}$.

\begin{tabular}{|l|l|l|l|l|}
\hline Coord. & \multicolumn{2}{|l|}{ UTM } & \multicolumn{2}{l|}{ Geográficas } \\
\hline Bocamina & $\mathrm{X}=648079,25$ & $\mathrm{Y}=4265526,32$ & $38^{\circ} 31^{\prime} 30,65^{\prime \prime} \mathrm{N}$ & $1^{\circ} 18^{\prime} 4,83^{\prime \prime} \mathrm{W}$ \\
\hline
\end{tabular}

Su acceso es sencillo si desde el núcleo urbano de Jumilla recorremos aproximadamente 5 kilómetros de la N-344 hacia Yecla. El minado de «Los Estanquicos» se localiza a unos 650 metros en línea recta de la margen derecha de esta vía, a la altura de la llamada pedanía de La Alquería que queda en la margen izquierda de dicha carretera. Este aprovechamiento estaba organizado como una sociedad de regantes que usaban el agua acumulada en los estancos (balsa) según turno o tanda de riego. Aproximadamente unas 60 hectáreas aprovechaban este sistema en el paraje de los Estanquicos y la Alquería, dedicados a olivar, viñedo y algún pequeño sector de huerta.

En la actualidad el aprovechamiento forma parte de la Comunidad de Regantes de «Miraflores», basada en la explotación de aguas subterráneas, tras la labor del IRYDA en los años setenta del siglo XX.

\section{2. Condiciones ambientales del entorno geográfico}

El sistema de la galería con lumbreras de «Los Estanquicos», es un claro ejemplo de galería filtrante asociada a rambla o cauce de flujo esporádico-espasmódico.

El trabajo de campo sitúa el cuerpo de la galería en la margen izquierda de la llamada Rambla del Gato o Rambla de La Alquería. Este ramblizo, caracterizado por un régimen hidrológico irregular y aleatorio, discurre encajado con dirección N-S a través del intravalle o corredor definido por la Sierra de la Cingla al norte y la Sierra de los Bujes al sur. El cauce de la rambla, coincide como no podía ser de otra manera con la línea que une los puntos de altitud menor del valle (talweg o vaguada), lugar de convergencia de los pidemontes enfrentados de ambos relieves.

Las sierras de Cingla y Bujes, ambas pertenecientes al dominio tectosedimentario del Prebético externo, desarrollan una configuración orográfica longitudinal de dirección general SW-NE. La altitud media de estas estribaciones no es elevada, ronda los $800 \mathrm{~m}$, aunque se alcanzan cotas superiores a 1000 en algunos puntos como el «Pico del Águila» o el «Picacho del Infierno».

El amplio trabajo de campo apoyado por la cartografía geológica y geomorfológica de la zona, permite enmarcar el sistema de la galería con lumbreras de «Los Estanquicos» en un área caracterizada por suelos cuaternarios integrados por materiales finos como arenas, limos y arcillas. Este tipo de material sedimentario, es el que rellena la mayor parte del

1 Mapa Topográfico Nacional, Hoja 844 - IV «La Alquería», escala: 1:25.000. Ministerio de Fomento, IGN. 
fondo del pequeño valle o corredor al que venimos refiriéndonos. Se han podido constatar igualmente trazas de material más gruesos como gravas y conglomerados calizos. Este tipo de material aflora en algunos puntos del lecho de la rambla, como parte de la carga sólida transportada por el caudal líquido esporádico de la rambla en episodios torrenciales anteriores (material de arrastre), y en los taludes propiamente dichos del ramblizo, como coluviones depositados en dichos geosistemas por gravedad. A medida que recorremos los pidemontes de los relieves adyacentes ascendiendo en altitud, son frecuentes las margas y margocalizas en las partes basales y las calizas dolomíticas en las partes más somitales (materiales cretácicos y del neógeno superior).

Este ámbito espacial se caracteriza por un clima mediterráneo continentalizado, influenciado por la cercanía del Mar Mediterráneo al este y la meseta de La Mancha al oeste. En cualquier caso, los relieves anteriormente descritos aunque de escasa altitud, limitan claramente el efecto moderador del aire marítimo que viene de levante. La temperatura media anual es de 16 grados centígrados, con inviernos fríos que alcanzan temperaturas bajo cero y veranos calurosos donde se superan los 40 grados. El periodo de heladas tiene lugar entre los meses de noviembre y marzo. Se trata de una climatología soleada y árida, con unas 3000 horas de sol al año y unas escasas lluvias, del orden de los $300 \mathrm{~mm}$ anuales.

La vegetación natural se ha visto muy afectada por las labores agrícolas, quedando reducida a unas pocas manchas de matorral, romero, brezos y plantas olorosas como el espliego. Las áreas de montaña registran algunas especies de porte arbóreo siendo el pino carrasco el más representativo.

\subsection{Rasgos del sistema: captación, circulación y distribución del agua}

El sistema de la galería con lumbreras de «Los Estanquicos», es un claro ejemplo de pozo horizontal del tipo galería drenante o «qanats», jalonado por pozos verticales, lumbreras o espejuelos, cuya presencia ventilan el sistema (respiraderos) y permiten al hombre la evacuación de materiales que con el paso del tiempo puedan obstruir el lecho del minado y por tanto el paso del subálveo.

Las mediciones topográficas realizadas en el campo a través de GPS y cinta métrica, constatan para este sistema hidráulico una longitud total o distancia real de 381,3 m desde la cabecera hasta la última lumbrera. La distancia planimétrica o reducida es lógicamente algo menor, algo más de 360 m, como constatan los visores cartográficos del IGN y los mapas topográficos.

La galería, que discurre con una dirección general N-S a través de un tramo de terreno con pendiente $1,3 \%$ o $0,75^{\circ}$, se compone de un número total de 8 lumbreras todas ellas de tipo circular.

Es factible que el sistema drenante pudiera albergar algún espejuelo más ya que se han constatado derrumbes y socavones en alguno de sus tramos. En cualquier caso, la mayor parte de ellas se conservan en mal estado, no existiendo protección alguna para sus bocanas. La profundidad de las mismas, se reduce paulatinamente conforme descendemos en altitud en dirección a la bocamina (Figura $n^{\circ} 3$ )

Las distancias parciales de lumbrera a lumbrera son muy variables, siendo las más cortas las desarrolladas entre la lumbrera 2 y 3 con 25,3 metros y entre la 3 y 4 con 35,4. Las parciales mayores corresponden a las acotadas entre la 5 y la 6 con 122,4 metros, y entre la 6 y la 7 con 167 .

La galería ha sido funcional hasta hace pocos años, pero hoy permanece seca debido a que el sistema como dijimos presenta numerosos hundimientos y derrumbes a lo largo de su recorrido. Se han constatado hasta cuatro hundimientos: uno antes de la presa de 
SISTEMAS DE LA GALERÍA CON LUMBRERAS DE LOS ESTANQUICOS (VISTA EN PLANTA)

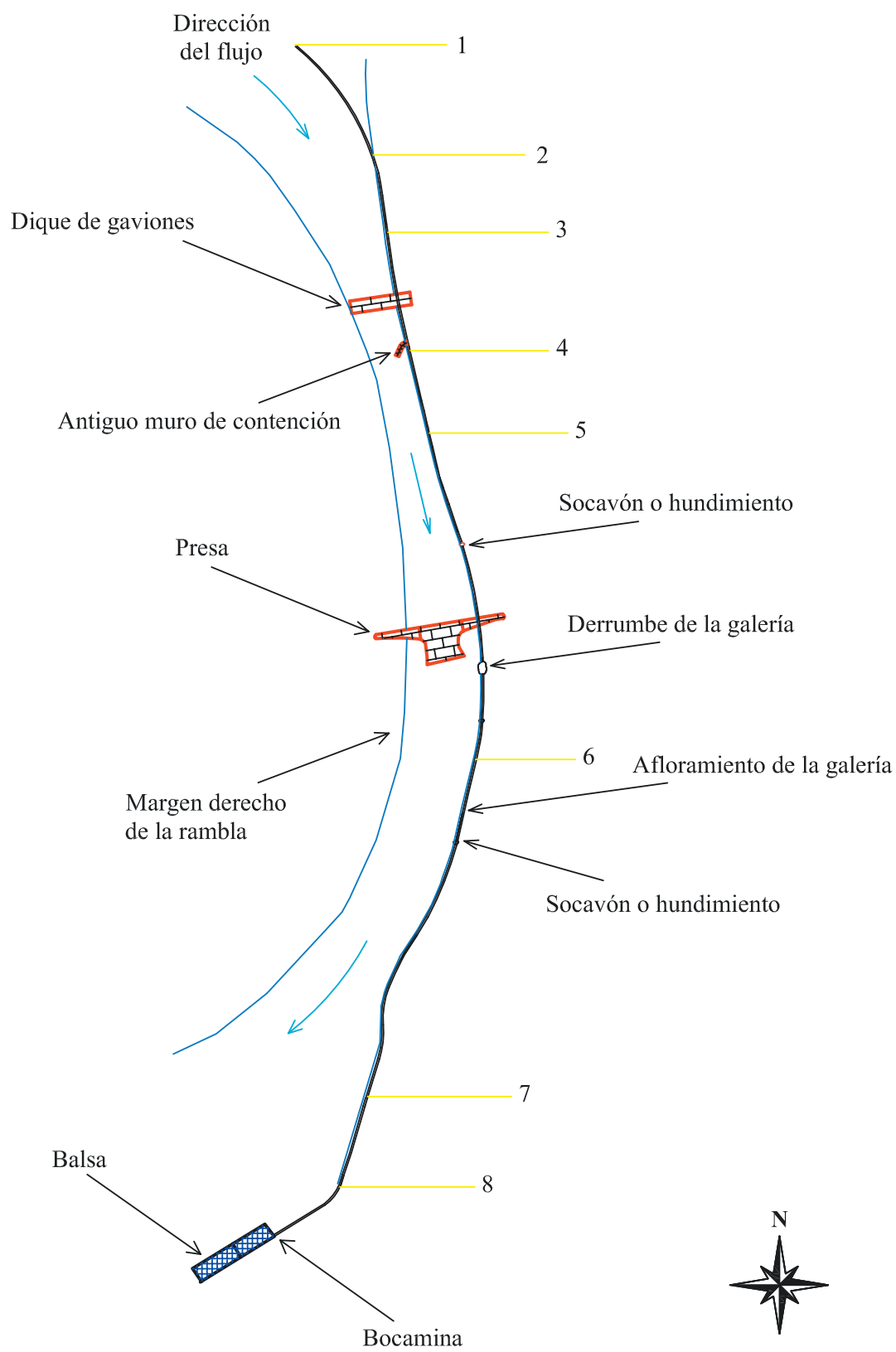

Escala 1:2.300

$70 \mathrm{~m}$

FIGURA $\mathrm{N}^{\mathrm{o}}$ 3. Dibujo en planta del minado de los Estanquicos. 


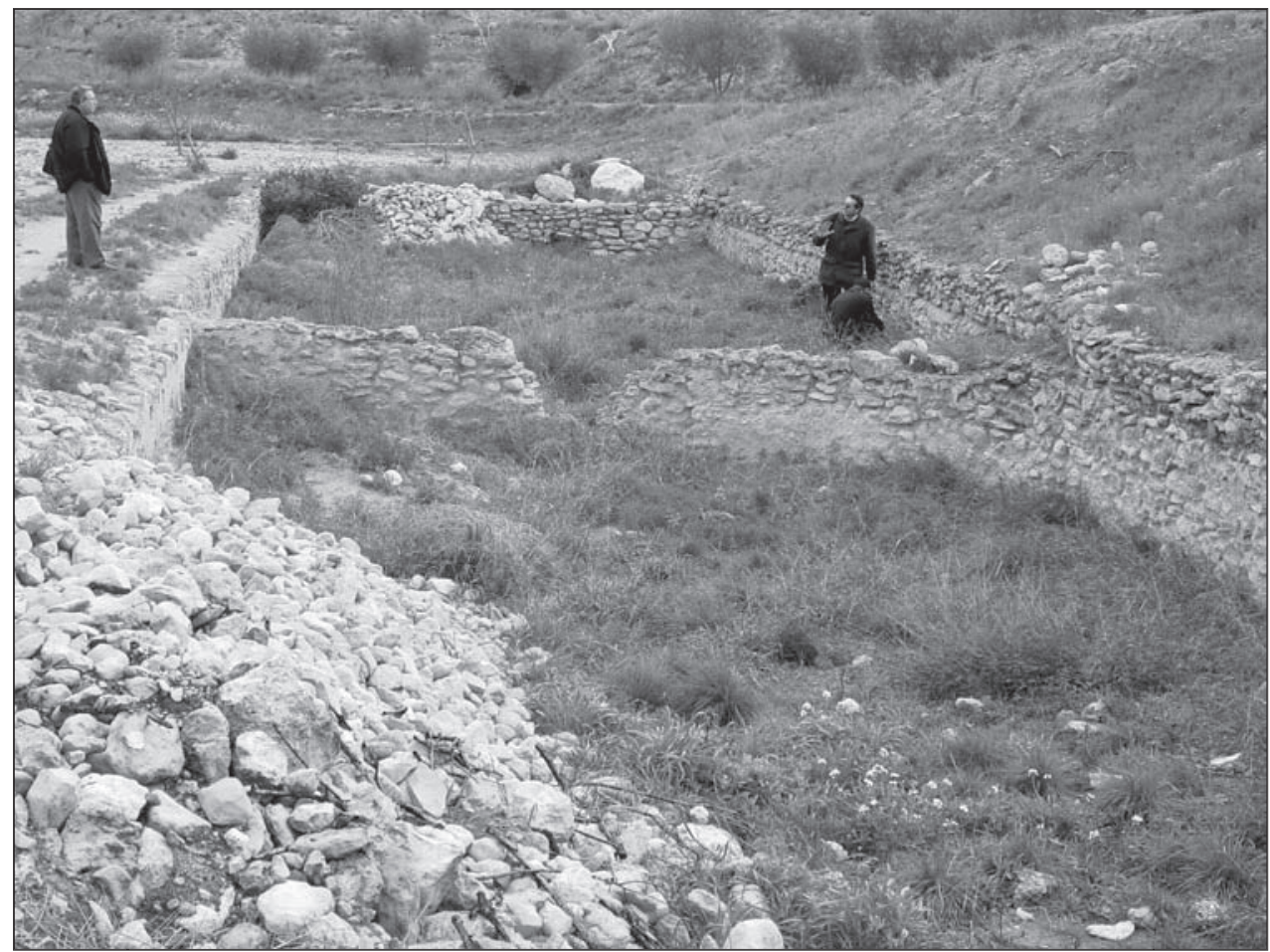

Fото $\mathrm{N}^{\mathrm{o}}$ 6. Balsa de los Estancos, final del sistema drenante de Los Estanquicos.

hormigón y tres más hacía el final de la galería, algo que ha favorecido el afloramiento en superficie de alguno de sus tramos.

El pozo horizontal del sistema drenante, posicionado como dijimos en la margen izquierda de la rambla, pasa por debajo de 2 obras artificiales de corrección y estabilización de cauces: un dique de gaviones y una presa de hormigón (Figura $n^{\circ} 4$ ).

La construcción de estas 2 obras hidráulicas en la Rambla de La Alquería por tanto no están tanto orientadas al embalse, más o menos permanente, de caudales líquidos, sino más bien buscan dar respuesta a la tipología de problemas asociados a la consolidación de márgenes y lecho del ramblizo, y a la retención de caudales sólidos. En cualquier caso, y sin perder de vista esta idea general, está claro que el dique de gaviones que hallamos entre la lumbrera 3 y 4, está más orientado a la retención de sólidos, y la presa de hormigón registrada entre la lumbrera 5 y 6 más hacia la retención de caudales líquidos (laminación de avenidas)

La lumbrera número 4 está además marcada por la presencia de un antiguo muro de protección, construido con elementos pétreos cementados con barro. Es difícil saber si este muro atravesaba transversalmente la totalidad de la rambla, o si más bien funcionaba como una especie de espigón protector de la galería. Con mucha probabilidad esta última hipótesis sea la más acertada, ya que curiosamente sólo se hallan los restos de este muro en la margen izquierda del cauce lugar donde precisamente se inscribe el minado subterráneo.

Todo el sistema de galería con lumbreras así descrito desemboca en una balsa receptora del flujo subálveo, conocida con el nombre de «estanquicos». El aguadero se divide en dos 
receptáculos de planta geométrica rectangular separados por un muro central que lamina el caudal líquido alumbrado, a la vez que sirve como obstáculo para los caudales sólidos transportados. De esta manera el primero de los dos recipientes funciona como balsa decantadora y el segundo como receptor del agua ya limpia y decantada (Foto $\mathrm{n}^{\circ} 6$ ).

Las mediciones en el campo confirman las siguientes dimensiones:

- Primer receptáculo o «balsa decantadora»: longitud 18 metros, anchura 6 metros (superficie en planta $108 \mathrm{~m}^{2}$ ), profundidad 0,9 metros (volumen 97,2 $\mathrm{m}^{3}$ ).

- Segundo receptáculo: longitud 21 metros, anchura 7 metros $\left(147 \mathrm{~m}^{2}\right)$, profundidad 1,4 metros (volumen 205,8 $\mathrm{m}^{3}$ ).

La bocamina o salida de la galería, hoy cubierta parcialmente por sedimentos, llega hasta la misma balsa receptora del subálveo alumbrado (salida directa a la balsa). No existe por tanto ninguna canalización que conduzca el agua alumbrada a cielo abierto desde la bocamina hasta la balsa como ocurren en otros sistemas drenantes de este tipo.

\subsection{Contexto geo-histórico del aprovechamiento}

En el estudio y análisis de los registros de propiedad y escrituras no hemos podido datar con exactitud el origen de este sistema hidráulico. Los registros sólo hablan de un origen inmemorial del aprovechamiento, mientras que diversas entrevistas realizadas a naturales de la zona estiman el origen de la galería en el siglo XIX.

Por las estructuras de los estancos y los materiales empleados en el reboque de las paredes, parece muy antigua esta balsa, relacionada con «villae» hispano-romanas.

Según Confederación Hidrográfica del Segura, con el agua de este sistema se riegan desde hace décadas bancales de viñedos, olivos y almendros en los márgenes y desembocadura de la Rambla de la Alquería (Jumilla). Hoy sin embargo, el sistema no drena ningún volumen de agua al exterior.

\subsection{Estado actual y observaciones}

Sin lugar a dudas, tanto hoy como antaño este tipo de sistemas hidráulicos representan un ejemplo claro de aprovechamiento integral y sostenible en el uso del agua. Son sistemas locales generadores de recursos propios de agua, de una gran calidad.

Como hemos comentado, el sistema de galería con lumbreras de Los Estanquicos, no es actualmente funcional debido a los numerosos derrumbes y hundimientos que presenta el sistema a lo largo de alguno de sus tramos. Se han constatado socavones que favorecen el afloramiento del minado en superficie, con plantas rectangulares de hasta 10 X 5 metros.

Éstas y otras observaciones permiten evaluar el mal estado de conservación del sistema drenante de los Estanquicos, que proporcionó agua para abastecimiento y riego en el paraje de La Alquería de Jumilla.

\section{Conclusiones}

En Jumilla y su entorno se han localizado una serie de galerías filtrantes llamadas aquí «minados con espejuelos», relacionadas con abastecimiento de ganados (Montesinos, Los Álamos, Los Manaores), con abastecimiento de personas, en pequeños núcleos rurales, (La Alquería, Fuente del Pino), y también para completar las necesidades hídricas de algunos cultivos (Los Estanquicos, Los Inques). 


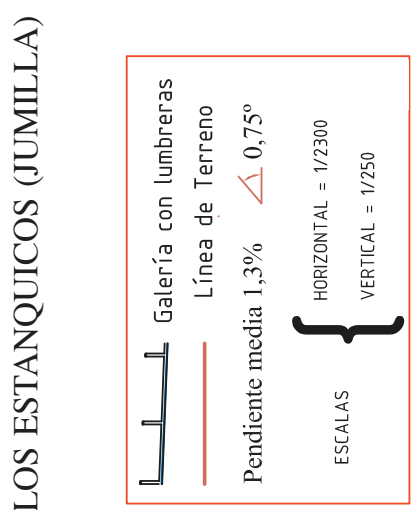

똠

告

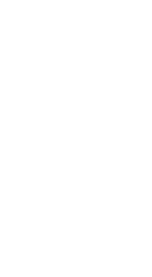

选

崩

$\sum_{\substack{1 \\ 0}}^{\mathbb{S}}$

空

范

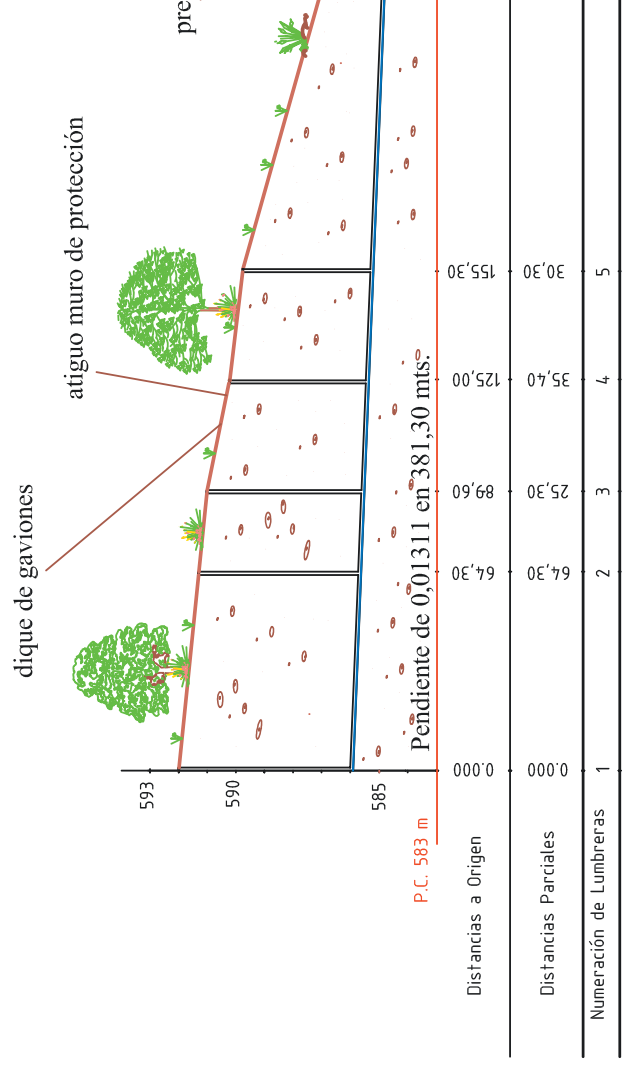

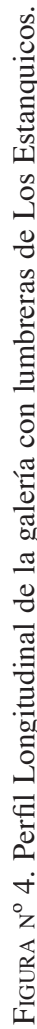


Estos sistemas locales de recursos propios de agua, se localizan aprovechando la escorrentía subsuperficial que converge en talweg como en el caso de Los Estanquitos, (galería filtrante asociada a un cauce del tipo rambla); con una longitud de minado que supera los 360 metros; y sobre todo con una balsa (estanque) muy peculiar, subdividida en dos áreas: la de decantación y la de acumulación. Otros se ubican exclusivamente en piedemontes, como los del núcleo de La Alquería, en los depósitos de ladera meridionales de la Sierra de la Cingla. Varios minados entre los que sobresale el de La Alquería propiamente dicho, con más de 820 metros de minado y 19 lumbreras o espejuelos, a los que había que sumar el minado lateral con otros 7 espejuelos. Sistema que aportaba agua a la Fuente de la Alquería y desde aquí a una balsa para riego. En este glacis se han situado otras galerías de menor dimensión como la de la «Casa de la Huerta», que movía las piedras de una almazara, o la del Estanco, con su balsa al otro lado de la carretera de Jumilla a Yecla.

Próximo a La Alquería, se encuentra el conjunto de los Manaores-Fuente del Pino, funcional hasta que a mediados del siglo XX la explotación de aguas profundas «Sociedad de Santa Clara» generó una bajada de niveles en el acuífero que afectaba al abrevadero concejil y al lavadero, por lo que la tanda de 28 días contemplaba el llenado del abrevadero y los sábados se echaba agua gratis al lavadero.

En definitiva, toda una serie de galerías filtrantes «qanat-s», denominadas como minados con espejuelos que constituían una fuente de recursos propios a nivel local, algunos de ellos todavía funcionales: La Alquería, Estanco, Fuente del Pino, Los Álamos, Montesinos. Y otras testigos de un aprovechamiento hidráulico: Los Estanquitos, Los Manaores, Los Inques.

\section{Bibliografía}

GIL MESEGUER, E.; GÓMEZ ESPÍN, J.Mª; (1993): «Galerías con lumbreras en el Sureste de España». Papeles de Geografía, nº 19. Págs. 125-146.

GIL MESEGUER, E.; GÓMEZ ESPÍN, J.Mª.; (Coordinadores). (2006): Modelos de Sostenibilidad en el uso del agua en la Región de Murcia. Colección: Usos del agua en el territorio. $\mathrm{N}^{\mathrm{o}} 3$. Universidad de Murcia. 159 pp.

GÓMEZ ESPÍN, J.M‥; (2004): Aprovechamiento integral del agua en la Rambla de Nogalte. (Puerto Lumbreras-Murcia). Colección: Usos del agua en el territorio. № 1 . Universidad de Murcia. 190 pp.

GÓMEZ ESPÍN, J.Mª ; (2004, a): «Sostenibilidad en el uso del agua en el territorio frontera de los antiguos reinos de Granada y Murcia». Papeles de Geografía, nº 40. Págs. 49-66.

GÓMEZ ESPÍN, J.M (2005). «Galerías asociadas a presas subálveas generadoras de recursos de agua en el sureste de la Península Ibérica. El modelo del sistema de la Rambla de Béjar». Nimbus, ${ }^{\circ}$ 15-16. Almería. Págs. 101-120.

GÓMEZ ESPÍN, J.Ma; LÓPEZ FERNÁNDEZ, J.A.; (2006): «Galerías con lumbreras en el área central de la Región de Murcia». Papeles de Geografía, nº 43. Págs. 31-59.

HERMOSILLA PLA, J. (Coordinador). (2006): Las galerías drenantes del Sureste de la Península Ibérica. Uso tradicional del agua y sostenibilidad en el Mediterráneo español. Ministerio de Medio Ambiente. Departamento de Geografía. Universidad de Valencia. 227 pp.

MORALES GIL, A. (1972): El Altiplano de Jumilla-Yecla. Departamento de Geografía. Universidad de Murcia. 467 pp.

PALERM-VIQUEIRA, J. (2004): «Las galerías filtrantes o qanats en México: Introducción y tipología de técnicas». Agricultura, Sociedad y Desarrollo. Volumen I, nº 2. Julio-Diciembre 2004. Págs. 133-145.

ROTH, D; SCHÜTT, B. (2001): «Las galerías con lumbreras (qanat): obras maestras de la ingeniería rural amenazadas». Revista Velezana, n 20. Vélez Rubio. Págs. 53-64. 